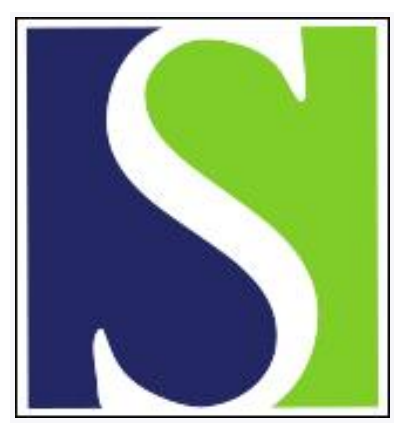

Scand J Work Environ Health 1983;9(4):333-340

https://doi.org/10.5271/sjweh.2406

Issue date: Aug 1983

Monitoring exposure to chromic acid in chromeplating by measuring chromium in urine.

by Lindberg $E$, Vesterberg $O$

This article in PubMed: www.ncbi.nlm.nih.gov/pubmed/6605579

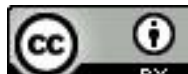




\title{
Monitoring exposure to chromic acid in chromeplating by measuring chromium in urine
}

\author{
by Erik Lindberg, MD, ${ }^{1}$ Olof Vesterberg, $M D^{2}$
}

\begin{abstract}
LINDBERG E, VESTERBERG O. Monitoring exposure to chromic acid in chromeplating by measuring chromium in urine. Scand $j$ work environ health 9 (1983) 333-340. With personal air samplers, exposure to hexavalent chromium was measured in a group of eight chromeplaters during a period of $5 \mathrm{~d}$; urine samples were collected at all times of urination for $7 \mathrm{~d}$. The concentration of chromium in the urine increased from Monday morning to Tuesday afternoon and then remained constant within the group as a whole throughout the rest of the workweek. In a large group of 90 chromeplaters exposure was measured for $1 \mathrm{~d}$, and urine samples were collected before and after the workshift on Monday and Thursday of the same week. There was a correlation between the exposure and the concentration of chromium in postshift urine samples on Thursday (correlation coefficient 0.71 ). Concentrations of chromium in urine of $\leq 100 \mathrm{nmol} / 1$ indicate timeweighted average values of exposure of about or below $2 \mu \mathrm{g} / \mathrm{m}^{3}$. Below this exposure no severe damage to the nasal septum and no influence on lung function have been found. After the initial measuring of the airborne hexavalent chromium and the concentrations of chromium in the urine of exposed workers, urine analyses are recommended for follow-up controls.
\end{abstract}

Key terms: biological exposure tests, occupational exposure.

Ever since the middle of the 19th century exposure to chromic acid and chromates has been known to carry the risk of damage to the airways, particularly the nose, with perforation of the septum. Connections between levels of exposure and nasal lesions were described by Bloomfield \& Blum in 1928 (2). More than 50 years later a more-detailed study of chromic acid exposure, airway symptoms, and lung function was made (Lindberg \& Hedenstierna, unpublished). Both subjective and objective symptoms were noted even at very low exposure levels (approximately $\left.1 \mu \mathrm{g} / \mathrm{m}^{3}\right)$. Chromates also have a carcinogenic effect (12).

1 Section of Occupational Medicine, National Board of Occupational Safety and Health, S-171 84 Solna, Sweden.

2 Chemistry Unit, National Board of Occupational Safety and Health, Solna, Sweden.

Reprint requests to: Dr E Lindberg, Section of Occupational Medicine, National Board of Occupational Safety and Health, S-171 84 Solna, Sweden.
It is a matter of immediate importance to have access to simple, reliable test methods for determining both the air content and biological uptake of chromic acid and chromates, ie, hexavalent (VI) chromium. Biochemical monitoring is particularly attractive, however, because (i) the total uptake is measured, including skin absorption (14), and (ii) most places of work are small and have only a few exposed workers, and air measurements are therefore costly.

In 1977 Berode \& Guillemin (1) reported some connections between chromium (VI) in the air and chromium levels in the urine of chromeplaters. These associations can be used to distinguish between low and very high levels of exposure by means of urinalysis. No reliable study of the low to moderately high exposure range $(<10$ $\mu \mathrm{g} / \mathrm{m}^{3}$ ) has been previously published.

The aim of the present investigation was to study the possibility of using urinary chromium concentrations as a measure of the total uptake and to study the correla- 
tion between chromium in the urine and air at low and moderately high concentrations. An effort has also been made to find a "discriminatory level" of urinary chromium that indicates low exposure according to air measurements.

Our study was begun when it was possible to measure urinary concentrations with good precision and reliability down to the levels in nonexposed individuals (18). The uncertainty of earlier methods of analysis is illustrated by the fact that investigations that are more than $2-3$ years old report "normal values" in nonexposed individuals which are about 10 to 100 times higher than those in more recent studies (table 1).

\section{Exposed subjects}

The investigation comprised a longitudinally monitored group of eight workers and a cross-sectionally studied group of 91 workers. Both groups worked on a day shift.

\section{Longitudinal study}

Eight male subjects at two factories were monitored continuously for $7 \mathrm{~d}$. The median age was 33 years, the range $17-59$ years. They were selected to represent the by far most common exposure range. The median exposure time was 4.5 years, the range 1.1-21 years.

\section{Cross-sectional correlation study}

The cross-sectional study group consisted of 91 persons, 15 of whom were women; it included all the workers who were exposed to chromic acid in 13 companies at the time of the investigation. The median

Table 1. Concentration of chromium in urine from nonexposed referents in different studies.

\begin{tabular}{lcc}
\hline Author & Year & $\begin{array}{c}\text { Chromium in urine } \\
(\mathbf{n m o l} / \text { ) }\end{array}$ \\
\hline Tipton et al (22) & 1969 & $\sim \overline{2}, 000$ \\
Völkl (25) & 1971 & $260 \pm 120$ \\
Franchini et al (7) & 1977 & $36 \pm 14$ \\
Guthrie et al (10) & 1978 & $6-24$ \\
Veillon et al (24) & 1979 & $5-10$ \\
Nomiyama et al (19) & 1980 & $9 \pm 8$ \\
\hline
\end{tabular}

age was 36 years, and the range $17-70$ years. The median exposure time was 5 years, the range $0.7-36$ years.

\section{Methods}

\section{Chromium in urine}

All urine samples were passed directly into 250-ml polyethylene bottles previously washed with nitric acid. Both urine samples and air samples were analyzed by our chemistry unit. The total concentration of chromium in the urine was determined by direct electrothermal atomic absorption spectrometry. The detection limit was about $5 \mathrm{nmol} / \mathrm{l}$. The coefficient of variation within the by far most common range $(20-400 \mathrm{nmol} / \mathrm{l})$ was about $3 \%$ (18). The chromium concentrations were adjusted to a standard urine density of 1.024 (6). The adjusted concentrations will be referred to in this communication as $\mathrm{U}-\mathrm{Cr}$.

The volume of the urine sample and the time of urination were also recorded.

\section{Exposure measurements and sampling strategy}

The sampling was done with glass fiber filters. The filters were leached in an alkaline buffer solution at $\mathrm{pH} 12$. After buffering to $\mathrm{pH} \mathrm{4}$, Zephiramin was added and the Zephiramin-chromium (VI) complex was extracted with methyl isobutyl ketone. The solution was analyzed by atomic absorption. The sampling and assay procedures have been tested in the field with a large number of parallel tests in different industrial plants. No significant differences were discernible after the filters had been stored for different periods of time, ranging between $1 \mathrm{~d}$ and three months after collection of the sample, a finding which indicates that chromium (VI) was not reduced on the filter.

The limit of detection was $0.2 \mu \mathrm{g} /$ filter, corresponding to $0.2 \mu \mathrm{g} / \mathrm{m}^{3}$ over an 8 -h sampling period.

The glass fiber filter method was compared with sampling in an impinger bottle at $\mathrm{pH} 12$ and the same analytical procedure in all other respects. No significant differences between the methods were detectable. 
A large number of simultaneous samples were taken at fixed sampling points within the relevant concentration ranges. The deviations between different filters did not exceed $25 \%$. The major portion of the deviation is probably due to volumetric errors (4).

For measuring the total concentrations of chromium in the air, cellulose acetate filters were used for sampling. The analyses were performed with atomic absorption spectrometry (15).

In the continuously monitored group the exposure was checked with personal air samplers every day for one workweek. Separate urine samples from all times of urination were collected from Monday morning of the week of monitoring up to and including the following Monday morning.

For each morning and afternoon during the entire week linear regression lines were calculated for $\mathrm{U}-\mathrm{Cr}$ and the mean value of chromium (VI) in the air during the week up to the time of urination.

In the cross-sectional study all the exposed workers submitted urine samples immediately before and after their workshifts on Monday and Thursday.

In the same week, the total concentrations of chromium and chromium (VI) in the exposed workers' breathing zones were measured during one workshift with personal air samplers. Due to the low concentrations of chromium in the air, it was only possible to obtain mean values of the concentration for whole shifts. Shorter elevated levels of exposure could not be measured. In some cases when exactly the same job at the same place of work was done by more than one worker, only one of them wore a personal air sampler, and it was assumed that the exposure was the same for fellow workers. This procedure was applied because of insufficient resources to provide each worker with his or her own air sampler in some plants with many exposed subjects. Thus for 12 workers the exposure was estimated indirectly. They were all working far from the chrome baths under very homogeneous conditions, and their exposure was low.

All workers answered a questionnaire about their health, especially kidney disease and diabetes, prior to the analysis of
U-Cr. Their hands and forearms were inspected to disclose yellow-colored skin or chrome ulcers - typical lesions by chromic acid in skin chaps - indicating contamination with chromic acid and thus probable dermal uptake (14).

Correlations between chromium in the air and U-Cr were calculated. In order to get a more exclusive correlation between exposure by way of the airways and U-Cr, the correlations were also calculated after 33 workers with yellow hands or chrome ulcers were excluded.

One of the 91 workers in the cross-sectional study had diabetes and was excluded from the calculations because diabetes might influence chromium metabolism $(3,5)$. No subject had proteinuria or a history of kidney disease.

\section{Statistical methods}

Linear regression lines were fitted according to the least square method. Covariance analysis was performed according to Tatsuoka (21).

\section{Results}

\section{Continuously monitored group}

No one in the continuously monitored group had yellow hands or chrome ulcers at the time of the examination. The exposure range was between 1 and $10 \mu \mathrm{g} / \mathrm{m}^{3}$. On Monday morning before the start of work, U-Cr was, on the average, more than 10 times higher than in nonexposed subjects (fig 1 \& table 1). By Tuesday afternoon it had increased to a level at which it remained without significant deviation during the rest of the workweek.

When correlation lines were calculated for U-Cr various times during the week and the average exposure during the preceding week days, no significant difference could be found between the lines during the period from Tuesday afternoon to Friday afternoon. A covariance analysis of the difference between the lines gave $p=0.74$ with respect to slope and $p=0.96$ with respect to position. The slope of the lines varied between 0.011 and 0.017 and averaged 0.014 , which is close to the slope of 0.013 (the value later found in the crosssectional study).

Thus urine samples submitted some 


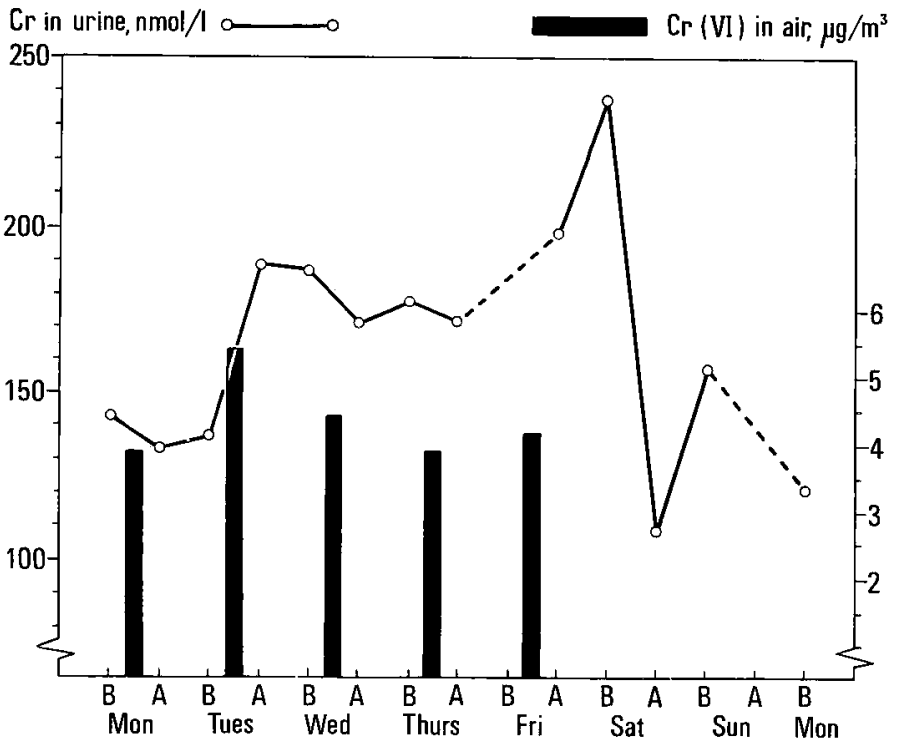

Fig 1. Mean daily values of exposure and the mean concentration of chromium in urine before and after the workshifts of a continuously monitored group $(\mathrm{N}=8)$ during a workweek and at the corresponding times during the weekend. Values on Friday morning and Sunday morning are excluded because of missing urine samples. $(B=$ before shift, $A=$ after shift)

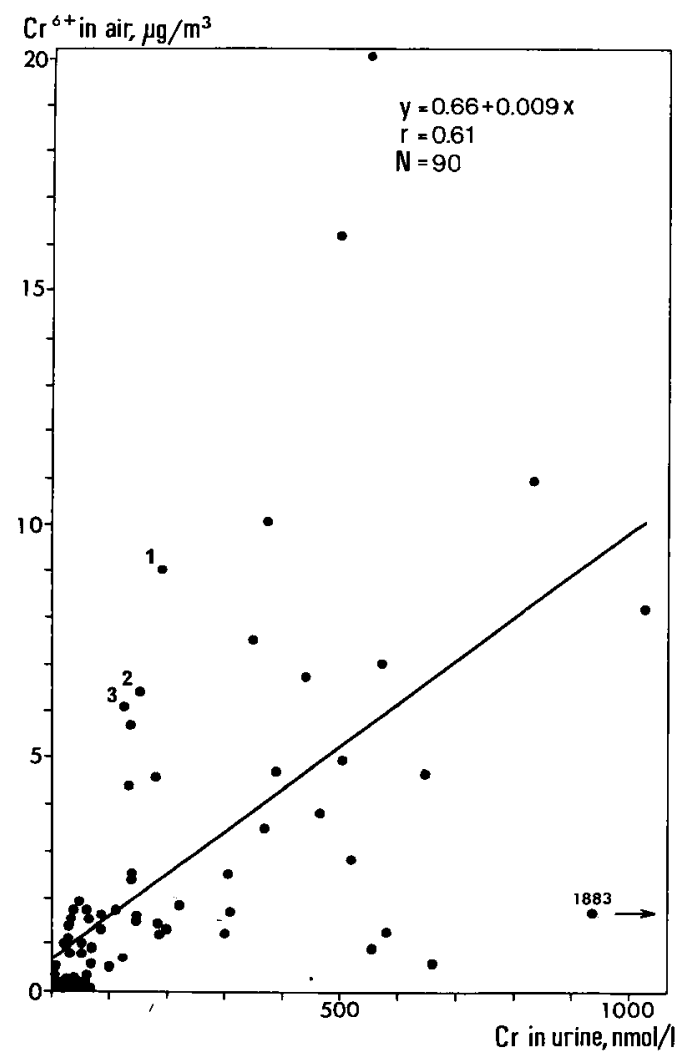

Fig 2. Correlation between chromium in the urine of the cross-sectionally studied group on Thursday afternoon and the mean exposure value for a representative day during the same week. $(r=$ correlation coefficient)

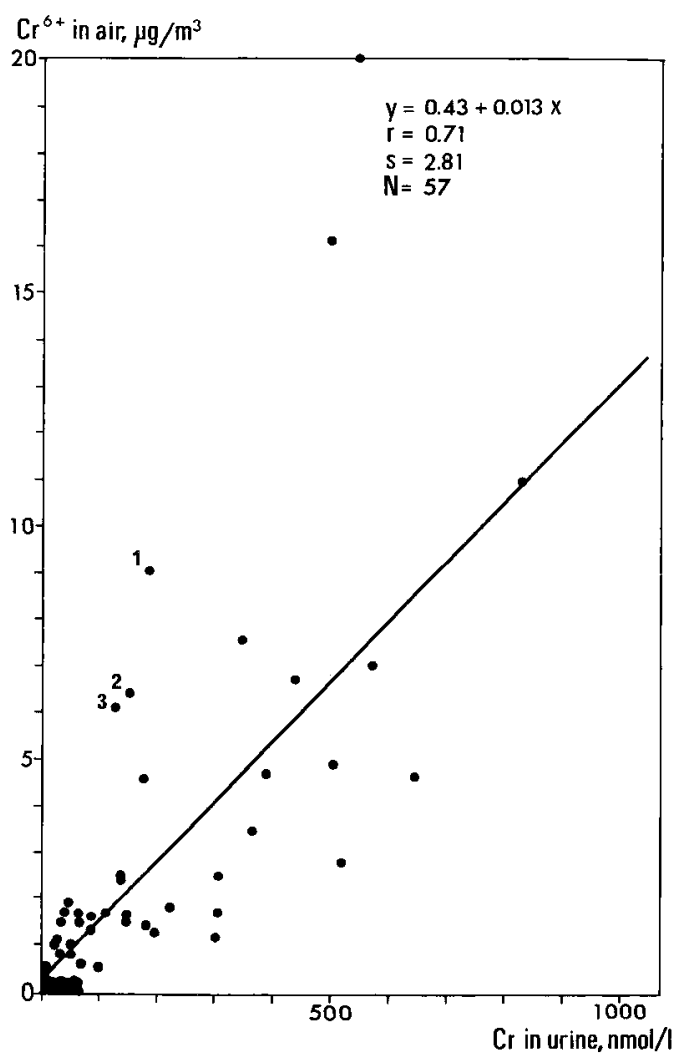

Fig 3. Correlation between chromium in the urine of the cross-sectionally studied group, excluding subjects with yellow hands or forearms, on Thursday afternoon and the mean exposure value for a representative day during the same week. $(r=$ correlation coefficient) 
time between Tuesday afternoon and Friday afternoon could be used to estimate the air exposure.

The previously mentioned correlations between $\mathrm{U}-\mathrm{Cr}$ and exposure were as good as those between total excretion of chromium per $24 \mathrm{~h}$ and exposure. In both cases the correlation coefficients on most days were on the order of 0.9 . However, single large deviations were obtained because of periods with increased excretion of chromium in the urine without simultaneously increased air concentrations.

\section{Cross-sectional study}

In the cross-sectional study comprising 90 persons, 68 were exposed to air concentrations of $<2 \mu \mathrm{g} / \mathrm{m}^{3}$. In three cases the exposure was $10-20 \mu \mathrm{g} / \mathrm{m}^{3}$, and in the remaining 19 cases it varied between 2 and $10 \mu \mathrm{g} / \mathrm{m}^{3}$.

There was a positive correlation between postshift U-Cr and the time-weighted concentration of chromium (VI) in the air. But the correlation was relatively low, and the variation was large, as can be seen in fig 2 .

The correlation was improved when 33 persons with skin obviously contaminated by chromium were excluded. The regression line was also steeper and approached that found for the continuously monitored group (fig 3 ).

When making correlations between chromium in the urine and exposure, we not only used the U-Cr values themselves but also the differences between $\mathrm{U}-\mathrm{Cr}$ values on Monday morning and Thursday morning or afternoon, respectively. However, the correlations thus found were considerably weaker than when the exposure was correlated directly with postshift U-Cr values. The correlations were practically uninfluenced if the 12 workers were excluded whose exposure was estimated indirectly.

The correlation between $\mathrm{U}-\mathrm{Cr}$ and total air chromium exposure was much weaker than between $\mathrm{U}-\mathrm{Cr}$ and the exposure to chromium (VI).

\section{Discriminatory level}

No exposed subjects with signs of ulceration of the nasal septum or impaired lung function were detected when the time- weighted air concentration was $<2 \mu \mathrm{g} / \mathrm{m}^{3}$ (Lindberg \& Hedenstierna, unpublished). Thus it was desirable to find a limit for $\mathrm{U}-\mathrm{Cr}$ values indicating an exposure of $<2 \mu \mathrm{g} / \mathrm{m}^{3}$. Mathematical methods for analyzing the correlation with confidence intervals are not adequate as the variation around the line is not homogeneous.

However, a confidence interval for the by far most common exposure range, at least in Sweden, ie, $<10 \mu \mathrm{g} / \mathrm{m}^{3}$, was calculated as a rough approximation. Thus three workers with extremely high exposures, who had worked at a very oldfashioned plant which has now been closed, were excluded. (An exposure of $>10 \mu \mathrm{g} / \mathrm{m}^{3}$ was not found in any other factory.) Three workers (numbered 1, 2 \& 3 in the figures) with a different kind of exposure were also excluded from the calculation at this time. They worked as a grinder, fitter, and pickler, respectively, and were exposed partly to poorly soluble chromates and chromium. (Most platers have a different exposure during some part of the workday. As there were no sharp limits between "mainly plating" and "mainly different exposure," it was not adequate to exclude any workers. Instead we made this note on the exposure.) Thus, with extreme and different exposures excluded, a $95 \%$ confidence interval, including 51 of the 57 individuals in fig 3 , gave an exposure of $\leq 1.8 \mu \mathrm{g} / \mathrm{m}^{3}$ at U-Cr $=100$ $\mathrm{nmol} / \mathrm{l}$. In the U-Cr range of $0-100 \mathrm{nmol} / \mathrm{l}$ the correlation with exposure appears to be very poor (fig 3 ).

\section{Discussion}

In our study the average U-Cr level was fairly constant from Tuesday through Friday after the workshifts (see fig 1). In earlier studies $(11,23) \mathrm{U}-\mathrm{Cr}$ was higher after the workshifts than before them. The higher concentrations in the evening apply, however, to exposure levels that were 10 times higher than those indicated by the urinary concentrations in our investigation. In two cases (23) the urinary concentrations were only $2-3$ times higher than in our series, and then the tendency towards higher evening values disappears almost entirely. The reason for this phenomenon may be that at high levels of exposure only a small proportion of the chro- 
mium (VI) is taken up by the blood cells (16) so that most of it remains in the plasma and gives rise to excretion peaks in the urine.

There is a similar study of chromeplaters (7) whose urinary excretion levels are about four times higher than in our series. In this case there was a sharp increase in $\mathrm{U}$-Cr during the first day of work after $4 \mathrm{~d}$ without exposure. During the fifth day of work the difference between morning and afternoon values was small. This finding tallies quite well with the overall picture.

The high U-Cr values on Friday afternoon and Saturday morning were due to high values in the three most heavily exposed workers. This result may have been caused by chance or may be due to skin contamination during cleaning-up work on Friday afternoon.

It is not surprising that the correlation between U-Cr and the actual exposure did not prove to be sufficiently high to allow individual computation of the air exposure level. Among other things, there was probably some absorption through the skin without it always being colored yellow. Furthermore, only a small portion of the inspired chromic acid mist consists of such small particles that it can be expected to diffuse far enough down into the lungs to allow complete absorption (Ekholm, Ulfvarson \& Lindberg, unpublished). Therefore a large and perhaps widely varying portion probably adheres to membranes in the respiratory tract and is brought up with the mucus and swallowed. Absorption from the gastrointestinal tract differs greatly from individual to individual. Thus after ingestion of soluble chromate the standard deviation of the serum concentrations can be greater than the mean (5).

The deviation of about $25 \%$ in the air measurements also contributes to the statistical variability.

Variations in diet can probably also increase the statistical variability. For example, glucose loading can almost double the excretion of chromium in the urine (9). It is also likely that the consumption of nutrients other than pure glucose can affect the excretion of chromium.

Part of the variability might be due to the fact that the air measurements could not always be done on Thursdays when the urine samples were turned in since the technicians had to distribute their work between various days of the week. However, if only "simultaneous" air and urine determinations are included, the correlation coefficient only increases from 0.71 to 0.75 .

No other special measures have been taken to reduce the variability so as to obtain "neat" results. On the contrary, the study includes the variations that occur under normal conditions.

The poor correlation with exposure within the $\mathrm{U}-\mathrm{Cr}$ range of $0-100 \mathrm{nmol} / \mathrm{l}$ may be caused by a relatively greater influence of dermal absorption when the air exposure is very low.

No correlation between the total period of exposure and U-Cr could be seen despite the fact that prolonged renal exposure to chromium can result in increased "chromium clearance" owing to impaired reabsorption in the renal tubules $(8,17)$. However, the increase in "chromium clearance" is probably the greatest at the beginning of exposure $(8,16)$. Only a few subjects had been employed for shorter periods than three months.

The exposure to chromium (VI) in stainless steel welding also involves the watersoluble form. Exposure to chromium (VI) in welding fumes appears to produce considerably lower U-Cr concentrations than the corresponding exposure in chromeplating (23). The explanation may be that the chromium (VI) in welding fumes is contained in a "matrix" of iron oxide (20) and is probably cleared from the airways to a considerably greater extent than the chromic acid mist. Only a few percent of swallowed chromium (VI) is absorbed (13). When chemical occupational health hazards are monitored at a particular place of work, there is always an element of uncertainty with both air and urine samples as to whether the findings are representative or not. This uncertainty is the most readily overcome with repeated urine samples. Repeated air sampling requires much greater personnel resources.

\section{Conclusion}

Since this study and an earlier one (14) show that dermal uptake of chromium (VI) is significant, systemic effects of chro- 
mium (VI) should correlate primarily with urinary concentrations. But airway symptoms can be presumed to be more dependent on inspired chromic acid than on total uptake. The desired goal of being able to use urinalyses to rule out exposure levels of more than $2 \mu \mathrm{g} / \mathrm{m}^{3}$ - and thereby the risk of nasal ulcerations and impaired lung function - has been attained with the limitation that $\mathrm{U}-\mathrm{Cr}$ concentrations of $\leq 100 \mathrm{nmol} / \mathrm{l}$ indicate a level of exposure around or below $2 \mu \mathrm{g} / \mathrm{m}^{3}$. This statement holds true if the exposure to chromium (VI) mainly involves the freely soluble chromic acid. If considerable amounts of sparingly soluble chromates are involved, the total exposure to chromium (VI) may be heavier than that indicated by $\mathrm{U}-\mathrm{Cr}$ (compare points $1,2, \& 3$ in fig 3 ).

When chromeplating plants are monitored, each work station should be investigated initially with both air and urine sampling. However, if both show low values, in most cases it should be possible to carry out further checks with urine samples for the intraindividual correlation between $\mathrm{U}-\mathrm{Cr}$ and exposure is good. Consequently it should be possible to make use of the results of this study to replace many costly and resource-intensive air concentration measurements with urinalyses.

\section{Acknowledgments}

We are very much indebted to Professors $\AA$ Swensson and C Hogstedt, and to L Hedström, statistician, for their generous advice and to $U$ Ekholm, engineer, for the air measurements.

\section{References}

1. Berode M, Guillemin M. Evaluation d'une exposition professionelle au chrome par le dosage du chrome urinaire. Med soc prev 22 (1977) $201-202$.

2. Bloomfield JJ, Blum W. Health hazards in chromium plating. Publ health rep 43 (1928) $230-251$.

3. Canfield W. Chromium, glucose tolerance and serum cholesterol in adults. In: Schapcott $\mathrm{D}$, Hubert J, ed. Chromium in nutrition and metabolism. Elsevier, Amsterdam, New York, and Oxford 1979, pp 145-161.

4. Christensson B, Krantz S, Kuusisto P, Undersökning av olika volymmätmetoder vid personburen provtagning [Investigation of different methods for measuring volumes in personal air sampling]. Arbetarskyddsstyrelsen (Swedish National Board of Occupational Health and Safety), Solna 1977. (Undersökningsrapport 1977: 16).

5. Doisy RJ, Streeten DHP, Souma ML, Kalafer ME, Rekant SI, Dalakos TG. Metabolism of chromium in human subjects. In: Mertx W, Cornatzer W, ed. Newer trace elements in nutrition. Marcel Dekker, New York, NY 1971, pp 155-168.

6. Elkins BH, Pagnotto LD, Smith HL. Concentration adjustments in urinalysis. Am ind hyg assoc $\mathrm{j} 35$ (1974) 559-565.

7. Franchini J, Cavatorta A, Mutti M, Marcato M, Botazzi D, Cigala F. Indici biologici de exposizione al cromo e rilievi dimici nell'industria di cromatura galvanica. Lav um 39 (1977) 141-151.

8. Franchini J, Mutti A, Cavatorta A, Corradi A, Cosi A, Olivetti G, Borgetretti A. Nephrotoxicity of chromium. Contrib nephrol 10 (1978) 98-110.

9. Gürson CT, Saner G. The effect of glucose loading on urinary excretion of chromium in normal adults, in individuals from diabetic families and in diabetics. Am $\mathrm{j}$ clin nutr 31 (1978) 1158-1161.

10. Guthrie BE, Wagne RW, Veillon C. Background correction and related problems in the determination of chromium in urine by graphite furnace atomic absorption spectrometry. Anal chem 50 (1978) 1900-1902.

11. Gylseth B, Gundersen N, Langård S. Evaluation of chromium exposure based on a simplified method for urinary chromium determination. Scand $j$ work environ health 3 (1977) 28-31.

12. International Agency for Research on Cancer. Chromium and chromium compounds: 3.1 Carcinogenicity studies in animals. Lyon 1980, pp 254-273. (IARC monographs on the evaluation of the carcinogenic risk of chemicals to humans, volume 23).

13. Langård S. Chromium. In: Waldron HA, ed. Metals in the environment. Academic Press, London 1980, pp 111-132.

14. Lidén S, Lundberg E. Penetration of chromium in intact human skin in vivo. $J$ invest dermatol 72 (1979) 42-45.

15. Lindstedt G. Kemiska analysmetoder inom det arbetshygieniska området [Methods for chemical analysis in occupational hygiene]. Arbetarskyddsstyrelsen, Solna 1978.

16. Mutti A, Lavatorta A, Borghi L, Canali M, Giaroli C, Franchini J. Distribution and urinary excretion of chromium. Med lav 3 (1979) 171-179.

17. Mutti A, Cavatorta A, Pedroni C, Borghi A, Giaroli C, Franchini J. The role of chromium accumulation in the relationship between airborne and urinary chromium in welders. Int arch occup environ health 43 (1979) 123-133.

18. Nise $G$, Vesterberg $O$. Direct determination of chromium in urine by electrothermal atomic absorption spectrometry. Scand $j$ work environ health 5 (1979) 404-410.

19. Nomiyama $\mathrm{H}$, Yotoriyama $\mathrm{M}$, Nomiyama 
K. Normal chromium levels in urine and blood of Japanese subjects determined by direct flameless atomic absorption spectrometry, and valence of chromium in urine after exposure to hexavalent chromium. Am ind hyg assoc j 41 (1980) 98-102.

20. Stern RM. Chromium (VI) analysis of fume matrices. In: The Danish Welding Institute. Occupational health risk assessment. Copenhagen 1981, pp 303-317.

21. Tatsuoka M. Multivariate analysis. John Wiley \& Sons Inc, New York, London, Sydney, Toronto 1971, pp 39-50.

22. Tipton IH, Stewart PL, Dickson S. Patterns of elemental excretion in long-term balance studies. Health phys 16 (1969) 455-462.
23. Tola S, Kilpiö J, Virtamo M, Haapa K. Urinary chromium as an indicator of the exposure of welders to chromium. Scand j work environ health 3 (1977) 192-202.

24. Veillon C, Wolf WR, Guthrie BE. Determination of chromium in biological materials by stable isotope dilution. Anal chem 5 (1979) 1022-1024.

25. Völkl A. Tages-Chromausscheidung von Normalpersonen. Zentralbl Arbeitsmed Arbeitsschutz Prophyl Ergon 21 (1971) 122.

Received for publication: 7 March 1983 